\title{
Uniform Deposition of Titanium Dioxide Films by Chemical Vapor Deposition (CVD)
}

\author{
M. S. Rahim, M. Z. Sahdan, J. Lias \\ Microelectronic and Nanotechnology Research Centre \\ Universiti Tun Hussein Onn Malaysia 86400 Batu Pahat, Johor, Malaysia \\ zainizan@uthm.edu.my \\ Z.Ahmad \\ Universiti Sains Malaysia, 11800 Nibong Tebal, \\ Pulau Pinang, Malaysia
}

Keywords- $-\mathrm{TiO}_{2} ; \mathrm{CVD}$; structural properties;UV-Vis

\begin{abstract}
Titanium is a lightweight metal with an outstanding combination of properties which make it the material of choice for many different applications. This paper investigates the structure, surface characteristics and electrical properties of the Titanium Dioxide $\left(\mathrm{TiO}_{2}\right)$ thin film, deposited by chemical vapor deposition (CVD). The deposition temperature was $1000^{\circ} \mathrm{C}$ with 3 different positions of the glass substrates. The surface morphologies were examined using a field emission scanning electron microscope (FESEM) and an atomic force microscopy (AFM). In order to investigate the structural properties, the $\mathrm{TiO}_{2}$ thickness was measured using a surface profiler. The optical properties of $\mathrm{TiO}_{2}$ were measured using an ultraviolet visible spectroscopy (UV-Vis). The surface morphology was found to be sensitive to the deposition parameters and the growth $\mathrm{TiO}_{2}$ is more uniform when the position of substrate is closed to the starting material.
\end{abstract}

\section{INTRODUCTION}

Energy sources such as coal, oil and natural gas is a popular source used nowadays. However, these non-renewable resources and energy sources is limited because there will always diminish every day. Therefore, the technology used to renew energy sources such as wind and solar power. Sunlight can be renewed by converting light into energy. Sunlight or solar energy can be used for heating and lighting, electricity generation, solar cooling, and a variety of commercial and industrial uses $[1,2]$. Solar cell (also called Photovoltaic) system is one promising option for future energy needs in a variety of technologies that are being developed at present. Solar cell also is a very fascinating because of high conversion efficiency produced by porous titanium dioxide $\left(\mathrm{TiO}_{2}\right)$ electrodes consisting of nanometer sized particles [3,4]. Titanium is preferred choice because of its higher strength to weight ratio, its corrosion resistance and its compatible expansion coefficient and electromotive force potential with graphite.

At present days, chemical vapor deposition (CVD) technique proved to be one of the best in producing of thin-film deposition in nano-form and is a lot of advantageous over other deposition techniques. CVD produces high purity and conformal coating at a moderate deposition rate [5]. To deposit desired material using CVD, Several parameters such as gas flow rate, precursor concentration, deposition temperature, pressure and substrate positioning should be considered for repeatable and high quality film.

In this work, the influence of substrate positioning was investigated. The surface morphologies, structural and optical properties were characterized [6].

\section{EXPERIMENTAL DETAILS}

The $\mathrm{TiO}_{2}$ films were synthesized using CVD technique on glass substrate. Before deposition process, the glass substrates were cleaned using acetone and placed on ultrasonic bath, in order to eliminate the organic residue. After that the glass substrate was rinsed with DI water and dried with nitrogen gas. 
The $\mathrm{TiO}_{2}$ film was prepared using titanium powder mixed with graphite and placed into alumina boat. Then, the alumina boat was inserted into the chamber. In order to investigate the effects of substrates position, three locations were used including $18 \mathrm{~cm}, 21 \mathrm{~cm}$ and $24 \mathrm{~cm}$ from the alumina boat (starting material). Chamber were heated by ramping with three different temperature levels from $300^{\circ} \mathrm{C}, 600^{\circ} \mathrm{C}$ and $1000^{\circ} \mathrm{C}$ with argon (Ar) gas flow to eliminate the atmospheric gas [7]. Then, Oxygen $\left(\mathrm{O}_{2}\right)$ gas was supplied into the chamber when the temperature was achieving $1000^{\circ} \mathrm{C}$. The deposition process was kept at 1 hour. All samples were characterized using atomic force microscopy (AFM), field emission scanning electron microscope (FESEM) and ultraviolet visible spectroscopy (UV-Vis).

\section{RESULTS AND DISCUSSION}

\section{A. Surface morphology}

Fig. 1 shows the three dimensional AFM images of the three different substrate position at 18 $\mathrm{cm}, 21 \mathrm{~cm}$ and $24 \mathrm{~cm}$. The images were recorded at the scan rate of $1 \mathrm{~Hz}$ on $3 \mu \mathrm{m} \mathrm{x} 3 \mu \mathrm{m}$ in truly non-contact mode. The average roughness for image in Fig. 1(a-c) is $7.588 \mathrm{~nm}, 9.965 \mathrm{~nm}$ and $13.581 \mathrm{~nm}$, respectively. This indicates that $\mathrm{TiO}_{2}$ surface morphology is influenced by the substrate position. It is observed that the thin film has good roughness if substrate is closed to the starting material. The surface morphology if Fig. 1 (a) is more uniform compared to the rest.

(a)

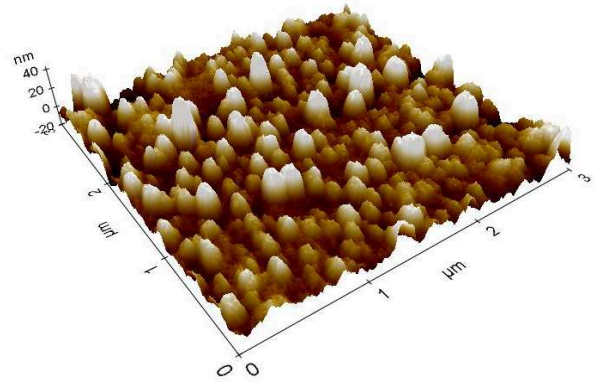

(b)



(c)

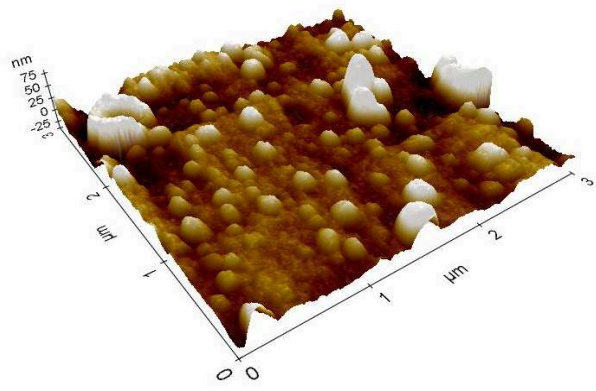

Fig.1. Atomic force microscopy (AFM) images of chemical vapor deposited $\left(1000^{\circ} \mathrm{C}\right.$ vaporizing temperature $) \mathrm{TiO}_{2}$ thin film at three difference placed a) $18 \mathrm{~cm}$, b) $21 \mathrm{~cm}$ and c) $24 \mathrm{~cm}$ from center of chamber.

The sample thickness was measured using a surface profiler and the average thickness of sample (ac) is $35.457 \mathrm{~nm}, 31.805 \mathrm{~nm}$ and $25.2145 \mathrm{~nm}$, respectively.

Fig. 2 shows the FESEM images of the $\mathrm{TiO}_{2}$ thin film grown at $1000^{\circ} \mathrm{C}$. Fig. 2(a) shows uniform distribution of square-like $\mathrm{TiO}_{2}$ particles. Whereas, Fig 2(b-c) shows the uniformity degradation as the position of the substrate was increased farther from the alumina boat. 


\section{B. Transmittance measurement}

Fig. 3 shows the optical transmittance of the $\mathrm{TiO}_{2}$ thin films deposited at $1000^{\circ} \mathrm{C}$ with three difference position of substrate which are $a=18 \mathrm{~cm}, b=21 \mathrm{~cm}$ and $c=24 \mathrm{~cm}$. The average thickness of all film is $30.8257 \mathrm{~nm}$. The measurement was performed at a wavelength ranged from $300 \mathrm{~nm}$ to 800 nm. Peak for $\mathrm{a}=101.48 \%, \mathrm{~b}=96.49 \%$ and $\mathrm{c}=98.79 \%$. The best transmittance for this substrate is $95 \%$ and above. All peak of $\mathrm{a}, \mathrm{b}$ and $\mathrm{c}$ will measure at a wavelength ranged from $333 \mathrm{~nm}$ to $340 \mathrm{~nm}$. Observation to the graph, graph decreased after reaching a peak and until $a=69 \%, b=70.72 \%$ and $\mathrm{c}=76.65 \%$.

(a)

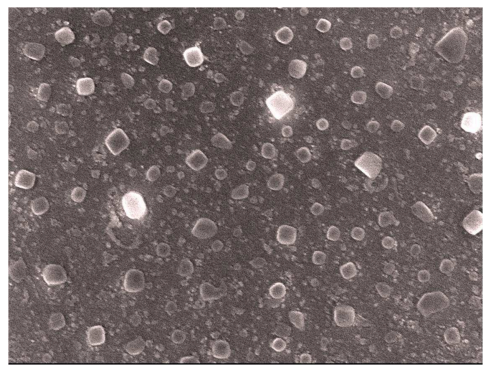

(b)

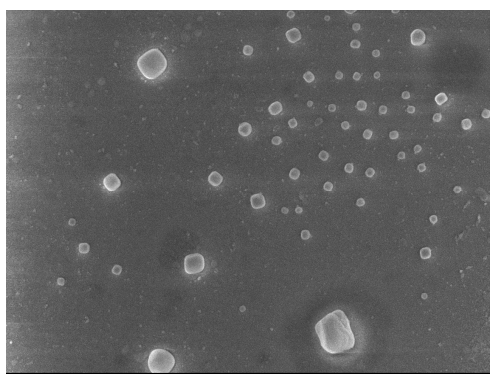

(c)

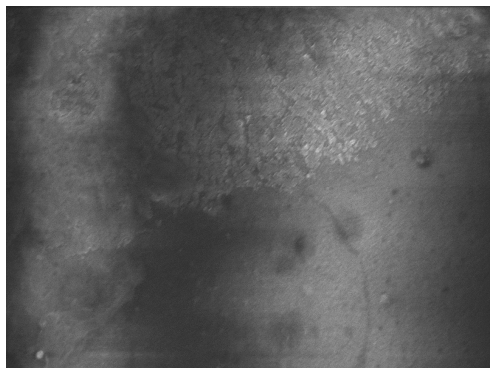

Fig. 2. Scanning electron microscopy (SEM) images of chemical vapor deposited $\left(1000^{\circ} \mathrm{C}\right.$ vaporizing temperature) $\mathrm{TiO}_{2}$ thin film with three difference placed of substrate. a), b) and c) is x30,000 magnification.

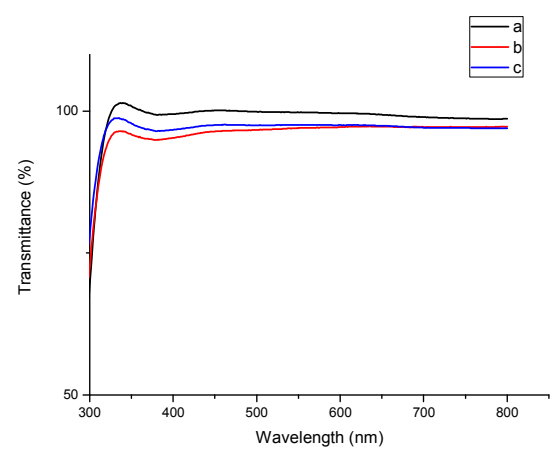

Fig. 3. Plot of transmittance versus wavelength for chemical vapor deposited $\left(1000{ }^{\circ} \mathrm{C}\right.$ vaporising temperature $) \mathrm{TiO}_{2}$ thin films with difference distance $a=18 \mathrm{~cm}, \mathrm{~b}=21 \mathrm{~cm}$ and $24 \mathrm{~cm}$. 


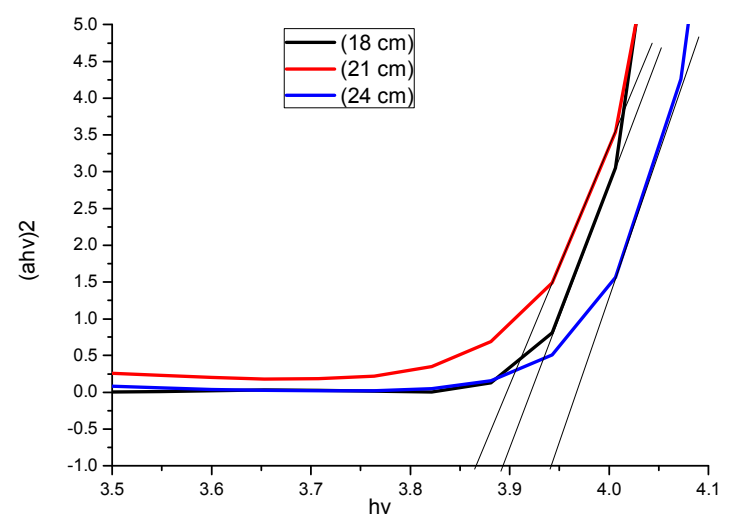

Fig. 4. . (Color online) $(\alpha h v)^{2}$ vs. hv plot of $\mathrm{TiO}_{2}$ films with different position of substrate.

The optical band gap energy of the films is calculated using the classical relationship for near edge optical absorption in semiconductors.

$$
\alpha \mathrm{h} v=\mathrm{K}(\mathrm{h} v-\mathrm{Eg})^{\mathrm{n} / 2}
$$

Where $\mathrm{K}$ is a constant, $\mathrm{h} v$ is photon energy, Eg is the optical band gap and " $\mathrm{n}$ " is a constant equal to 1 for direct band gap and 4 for indirect transitions. $(\mathrm{ahv})^{2} \mathrm{vs.} \mathrm{h} v$ plot of as-deposited TiO2 thin film is shown in Fig. 6.

The direct band gap is difference for each sample, three band gap shows the distance from center of chamber is $18 \mathrm{~cm}, 21 \mathrm{~cm}$ and $24 \mathrm{~cm}$. Band gap for $18 \mathrm{~cm}=3.89 \mathrm{eV}, 21 \mathrm{~cm}=3.86 \mathrm{eV}$ and $24 \mathrm{~cm}=$ $3.94 \mathrm{eV}$.

\section{CONCLUSION}

The uniformity of $\mathrm{TiO}_{2}$ films was investigated using different substrate positions which are $18 \mathrm{~cm}$, $21 \mathrm{~cm}$ and $24 \mathrm{~cm}$ from the starting material with average thicknesses of $35.457 \mathrm{~nm}, 31.805 \mathrm{~nm}$ and $25.2145 \mathrm{~nm}$, respectively. The deposition temperature was fixed at $1000^{\circ} \mathrm{C}$ using a chemical vapor deposition technique. The thin film has an average peak transmittance of $98.92 \%$. The uniformity of the film was obtained using substrate position of $18 \mathrm{~cm}$ from the starting material. The uniformity could be enhanced by optimizing other parameters such as the deposition time, mass of the starting material and gas flow rate

\section{ACKNOWLEDGMENT}

The authors would like to thank Ministry of Education Malaysia and Universiti Tun Hussein Onn Malaysia for the financial support through RAGS grant vot R003 and FRGS grant vote 1210.

\section{REFERENCES}

[1] Rousseau et al. Multi-donor molecular bulk heterojunction solar cells: improving conversion efficiency by synergistic dye combinations. Journal of Materials Chemistry, 2009; 19 (16): 2298 DOI: $10.1039 / \mathrm{b} 903189 \mathrm{~h}$

[2] Cheuk Wing Lee, Jin Zhong, Top down strategy for renewable energy investment: conceptual framework and implementation, Renewable Energy 68 (2014) 761-773.

[3] M.A.green, Energy policy 28 (2000) 989.

[4] Xiaoli Lui and Zhiyu Jiang, cylic voltammetric and AC Impedance Behaviour at $\mathrm{TiO}_{2}$ Electrodes under UV Illumination,journal of the chemical society, 2003, 50, 1003-1008. 
[5] H. Kashani*, M. Heydarzadeh Sohi, H. Kaypour, Microstructural and physical properties of titanium nitride coating produced by CVD process, Materials Science and Engineering A286 (2000) 324-330.

[6] P.S.Shinde, C.H.Bhosale, Properties of chemical vapour deposited nanocrystalline $\mathrm{TiO}_{2}$ thin film and their use in dye-sensitized solar cells, J. Anal. Appl. Pyrolysis 82 (2008) 83-88.

[7] H. Natsuhara, T. Tatsuyama, M. Ushiro, M. Furuhashi, T. Fujii, F. Ohashi, N. Yoshida, S. Nonomura, Preparation of $\mathrm{SnO} 2$ thin films at low temperatures with $\mathrm{H} 2$ gas by the hot-wire CVD method, Thin Solid Film 519 (2011) 4538-4541. 